\title{
Estado da arte dos aterros de resíduos sólidos urbanos que aproveitam o biogás para geração de energia elétrica e biometano no Brasil
}

\author{
State of art of landfills that use biogas for the \\ generation of electrical energy and biomethane in Brazil \\ Maria Cândida Barbosa Nascimento** $\odot$, Elcires Pimenta Freire', \\ Francisco de Assis Souza Dantas ${ }^{1} \stackrel{\oplus}{ }$, Miguel Bortoletto Giansante ${ }^{1}$
}

\begin{abstract}
RESUMO
O aproveitamento do biogás gerado a partir da decomposição da matéria orgânica dos resíduos sólidos urbanos (RSU), além de ser uma fonte renovável de energia, também contribui com a redução do lançamento de metano e do dióxido de carbono $\left(\mathrm{CO}_{2}\right)$ na atmosfera, que são importantes gases de efeito estufa (GEE). No entanto, o biogás é pouco explorado no país e seu potencial continua sendo controverso, principalmente devido às diferentes metodologias de avaliação adotadas. A pesquisa realizada mostra que, entre 2004 e 2015, foram implantadas nos aterros de resíduos do País somente 9 usinas termelétricas, que juntas geram 86,3 MW de energia elétrica, e duas usinas que produzem biometano. Considerando as estimativas existentes, o Brasil explora somente de 7 a 20\% do biogás produzido nos aterros de resíduos para fins energéticos.
\end{abstract}

Palavras-chave: aterro sanitário; biogás; energia renovável; gases de efeito estufa; resíduos sólidos urbanos; usinas termelétricas.

\begin{abstract}
The use of biogas generated by the decomposition of organic matter from urban solid waste, besides being a renewable source of energy, also contributes to the reduction of the methane and carbon dioxide's release into the atmosphere, which are significant greenhouse effect gases (GHG). However, biogas is little explored in the country and its potential remains controversial, mainly due to the different adopted methodologies of evaluation. This research shows that, between 2004 and 2015, only nine thermoelectric plants were implanted in waste landfills in the country, which together generated $86.3 \mathrm{MW}$ of electricity and two plants that produced biomethane. Considering the existing estimates, Brazil exploits only 7 to $20 \%$ of the biogas produced in landfills for energy purposes.
\end{abstract}

Keywords: sanitary landfill; biogas; renewable energy; greenhouse gases; urban solid waste; thermoelectric plants.

\section{INTRODUÇÃO}

O território nacional encontra-se intensamente urbanizado, visto que $84,4 \%$ da população reside nas zonas urbanas dos municípios e $15,4 \%$ nas zonas rurais (IBGE, 2011). Além disso, quase metade da população brasileira (44\%) concentra-se em municípios que possuem mais de 200 mil habitantes (IBGE, 2010), favorecendo assim a concentração da geração e da disposição final de resíduos sólidos urbanos (RSU), que são compostos, em média, de 52\% de matéria orgânica. Em 2014, o Brasil gerou cerca de 219 mil toneladas diárias de RSU (ABRELPE, 2015) e, portanto, cerca de $114 \mathrm{mil} \mathrm{t} /$ dia de resíduos orgânicos que foram confinados em aterros de resíduos, tornando-os grandes potenciais para a exploração de biogás e consequente fonte alternativa renovável para a geração de energia elétrica e/ou térmica. Segundo Reichert (2014), cada tonelada de resíduo disposto possui potencial energético da ordem de 0,1 a 0,2 MWh.

$\mathrm{O}$ atual cenário sobre as mudanças climáticas mostra a urgente necessidade de as autoridades nacionais colocarem a questão ambiental no centro dos debates de suas economias, buscando, dessa maneira, soluções ambientalmente adequadas que visem diminuir a dependência da utilização de combustíveis fósseis e não renováveis como fontes alternativas de energia. Destaca-se a utilização do metano presente no biogás, que, além de representar uma importante fonte alternativa de geração de energia, deixa de ser lançado na atmosfera, uma vez que é considerado um importante gás de efeito estufa (GEE). Se comparado

'Fundação Escola de Sociologia e Política de São Paulo - São Paulo (SP), Brasil

*Autor correspondente: mariacandida.bn@gmail.com

Recebido: 27/10/2016 - Aceito: 31/10/2017 - Reg. ABES: 171125 
ao dióxido de carbono $\left(\mathrm{CO}_{2}\right)$, possui potencial de aquecimento global 28 vezes superior, considerando o período de 100 anos (IPCC, 2014).

A produção de metano depende das características dos RSU (composição, tamanho das partículas, umidade, temperatura e $\mathrm{pH}$ ) e das técnicas de implantação e operação dos locais de disposição final. Ensaios realizados nos aterros sanitários de Caieiras e Santo André, ambos localizados no Estado de São Paulo, mostram que a produção de metano por tonelada de RSU foi de 99,69 m³ (PECORA; VELAZQUÉZ; COELHO, 2010) e 73,59 $\mathrm{m}^{3}$ (ICLEI, 2009), respectivamente.

$\mathrm{O}$ aproveitamento da biomassa dos RSU como fonte energética induz a melhoria nas condições operacionais dos aterros de resíduos e gera receita pela obtenção de créditos de carbono e venda de eletricidade. Contribui com a redução de outros gases lançados na atmosfera, como o sulfeto de hidrogênio, que emite odor desagradável, e o monóxido de carbono e hidrogênio, que são inflamáveis.

Embora o governo brasileiro tenha criado o Programa de Incentivos às Fontes Alternativas de Energia (PROINFA), por meio da Lei Federal $n^{\circ} 10.438 / 2002$ (BRASIL, 2002), a pesquisa realizada no presente estudo mostra que o País tem poucos projetos implantados para a geração de energia elétrica a partir do biogás, sendo que a maioria dos existentes faz parte do Mecanismo de Desenvolvimento Limpo (MDL) (BARIN, 2012).

No Brasil, entre 2004 e 2015, o biogás gerado nos aterros de resíduos foi explorado em 9 termelétricas, que produziram juntas 86,6 MW de energia elétrica, em duas usinas, que geraram 57 mil metros cúbicos diários de biometano, e em três aterros sanitários, que o utilizam como fonte de calor para a evaporação do lixiviado.

Nesse contexto, este artigo apresenta os resultados obtidos por meio de estudo sobre os projetos de aproveitamento de biogás nos aterros de RSU existentes no Brasil para geração de energia elétrica e biometano.

\section{ASPECTOS METODOLÓGICOS}

A presente pesquisa, realizada em três etapas, foi fundamentada em dados disponíveis em sites oficiais de entidades públicas e privadas, que direta e/ou indiretamente estão envolvidas na gestão de RSU, e em iniciativas de aproveitamento energético dos gases gerados nos aterros de resíduos do Brasil.

A primeira etapa se restringiu à obtenção de dados sobre a atual situação da geração e da disposição final dos RSU, da matriz energética brasileira e sua implicação no aumento das emissões de GEE e sobre o potencial energético dos aterros sanitários no país.

Já na segunda etapa, a pesquisa envolveu o levantamento dos projetos registrados no âmbito do MDL, com a Secretaria Executiva da Comissão Interministerial de Mudança Global do Clima, do Ministério da Ciência, Tecnologia e Inovação (BRASIL, 2015) e da United Nations Framework Convention on Climate Change (UNFCCC, 2015). Foram analisados os objetivos dos projetos (captura de biogás para queima em flares enclausurados, geração de energia elétrica ou biometano), as situações de seus registros (validação e/ou emissão de registros) e a obtenção de Certificados de Redução de Carbono (CER) pela queima ou pelo aproveitamento energético do biogás. Envolveu também a pesquisa em artigos técnicos, buscando identificar em quais aterros de resíduos o biogás vem sendo captado para aproveitamento energético.

Por fim, na terceira etapa, realizou-se a análise comparativa entre o potencial instalado e o estimado de geração de energia elétrica nos aterros brasileiros de resíduos.

\section{GERAÇÃO DE ENERGIA ELÉTRICA NO BRASIL E AQUECIMENTO GLOBAL}

As fontes de geração de energia elétrica no Brasil durante os anos de 2013 e 2014 sofreram consideráveis alterações, ocasionadas principalmente pelas condições climáticas desfavoráveis, que reduziram a oferta hídrica no País, e pelo aumento de 2,9\% no consumo de eletricidade em 2014 (EPE, 2015). Mesmo com o incremento de 3.177 MW na produção de energia no parque hidrelétrico nacional, que foi instalado durante esses anos, nota-se, pela Figura 1, que, em 2014, a participação de fontes renováveis (hidráulica, eólica, biomassa e nuclear) sofreu recuo de $4,6 \%$ na matriz nacional se comparada ao ano de 2013, mesmo com o aumento de $85,6 \%$ da participação da energia eólica. Por outro lado, as fontes de energia não renováveis que queimam combustíveis fósseis (térmicas a óleo diesel, gás natural e carvão), consideradas importantes fontes causadoras do aquecimento global, aumentaram em média 19,8\%. A produção das usinas térmicas movidas a óleo diesel e carvão mineral aumentaram em 43,2 e 24,2\%, respectivamente (EPE, 2015).

De acordo com o Relatório sobre o Estado da Temperatura de 2014, publicado pela Sociedade Meteorológica Americana (Ecodesenvolvimento, 2015), a temperatura média anual mundial atingiu o seu ponto mais quente em 135 anos, com registros recordes de calor em todo o mundo, com exceção do leste da América do Norte, que manteve temperaturas abaixo da média anual. Os oceanos também atingiram recordes de calor e acentuada elevação do nível do mar.

O Balanço Energético Nacional de 2015 mostra que, em 2014, a capacidade instalada de energia elétrica oriunda de fontes renováveis foi de 133.914 MW (EPE, 2015), sendo que 12.686 MW corresponderam à gerada a partir da biomassa (agroindustriais, óleos vegetais, florestas, resíduos animais e RSU) (ANEEL, 2015b).

\section{GERAÇÃO E DISPOSIÇÃO FINAL DOS RESÍDUOS SÓLIDOS URBANOS}

A Região Sudeste abriga $42 \%$ da população brasileira e coleta praticamente a metade $(52,6 \%)$ do volume total de RSU gerados no Brasil, 
que são dispostos predominantemente (73\% do total) em aterros sanitários. Em seguida, a Região Nordeste, com $27,7 \%$ da população, coleta cerca de um quarto dos RSU (22,1\%), que são dispostos, em sua maioria, (64,3\%) em lixões e aterros controlados (condições inadequadas), conforme mostra a Tabela 1.

\section{MECANISMO DE DESENVOLVIMENTO LIMPO}

Em 1997, foi redigido o Protocolo de Quioto, que estabeleceu a redução da emissão dos três principais GEE responsáveis pelo aquecimento global: o gás carbônico $\left(\mathrm{CO}_{2}\right)$, o metano $\left(\mathrm{CH}_{4}\right)$ e o dióxido de nitrogênio $\left(\mathrm{NO}_{2}\right)$. O CO 2 é o maior contribuinte do total das emissões de GEE dos países desenvolvidos, devido à queima de combustíveis fósseis. Em segundo lugar está o $\mathrm{CH}_{4}$, que possui potencial de aquecimento global 21 vezes superior ao do $\mathrm{CO}_{2}$ (IPCC, 1996) e é gerado nos aterros de RSU, nas estações de tratamento de esgotos (ETE), pela pecuária (dejetos de animais) e pela agricultura (vinhoto).

Visando reduzir as emissões de GEE, foram criados três mecanismos de flexibilização, sendo que dois são voltados aos países desenvolvidos com metas de redução estabelecidas e acordadas (Comércio de Emissões ETU - e Projetos de Implementação Conjunta - JI) e o terceiro, de interesse no presente trabalho, denominado de Mecanismo de Desenvolvimento Limpo (MDL), que é voltado aos países em desenvolvimento.

Os projetos do MDL são elegíveis sob o conhecido Mercado Internacional de Carbono, que tem, como alguns dentre diversos objetivos, a queima e o aproveitamento energético do biogás gerado nos aterros, que recebem Certificados de Redução de Emissão (CER) por cada tonelada métrica de $\mathrm{CO}_{2}$ não emitida, reduzida ou sequestrada. Em termos mundiais, o país destaca-se como o terceiro a deter o maior número de projetos aprovados e registrados (4,74\% do total) pela Organização das Nações Unidas (ONU), perdendo somente para a Índia (19,85\%) e China (48,94\%) (ABRELPE, 2012).

A pesquisa realizada com o MCTI e a UNFCCC mostra que foram registrados 59 projetos do MDL visando à captação de biogás, sendo que 31 (52\% do total) são voltados à geração de energia elétrica e biometano; 8 (14\%), à queima do biogás em flare(s) enclausurado(s), com possibilidade futura de gerar energia elétrica ou biometano; e 20 (34\%), somente à queima do biogás (BRASIL, 2015; UNFCCC, 2015).

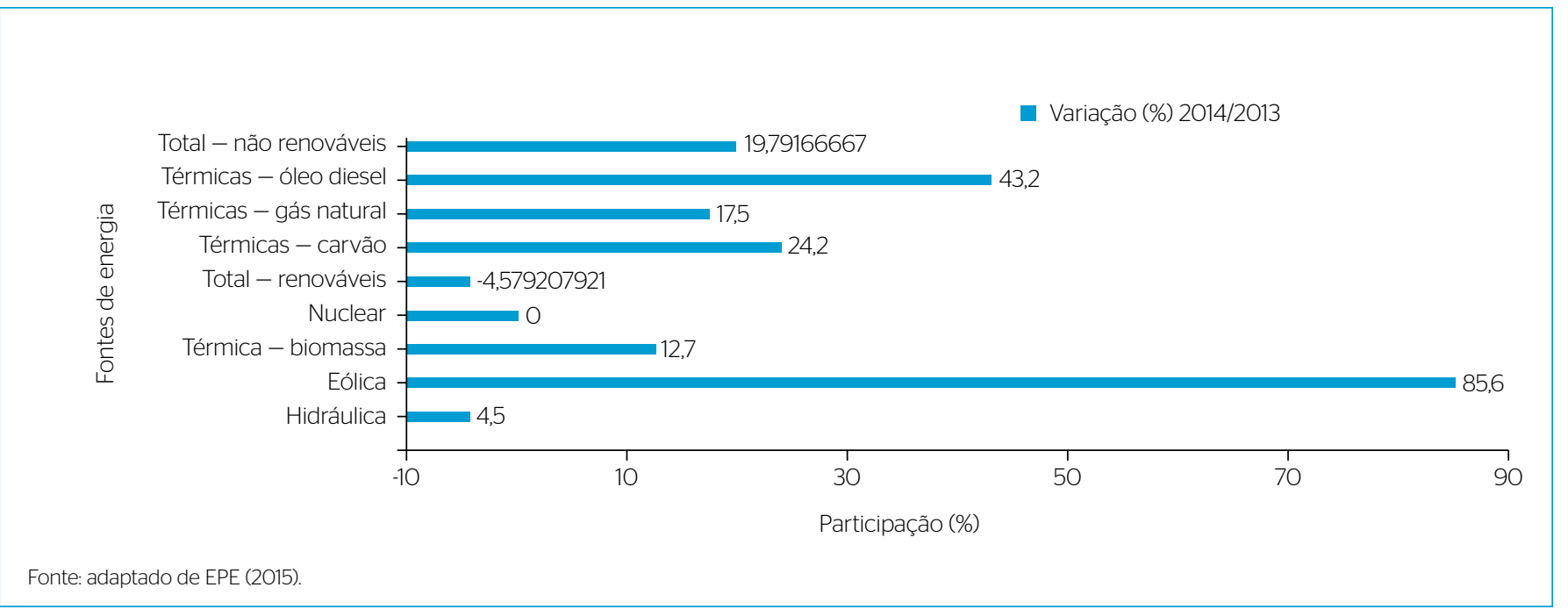

Figura 1 - Variação da participação (\%) das diversas fontes de geração de energia elétrica no País entre os anos de 2004 a 2013.

Tabela 1 - População, quantidade de resíduos coletados e formas de disposição final dos resíduos sólidos urbanos no Brasil.

\begin{tabular}{|c|c|c|c|c|c|c|c|c|}
\hline \multirow{3}{*}{ Região } & \multicolumn{2}{|c|}{ População (IBGE, 2010) } & \multicolumn{2}{|c|}{ Resíduo coletado } & \multicolumn{4}{|c|}{ Disposição final } \\
\hline & \multirow{2}{*}{ Habitantes } & \multirow{2}{*}{$\%$ total } & \multirow{2}{*}{$\mathrm{t} / \mathrm{dia}$} & \multirow{2}{*}{$\%$ total } & \multicolumn{2}{|c|}{ Lixão e aterro controlado } & \multicolumn{2}{|c|}{ Aterro sanitário } \\
\hline & & & & & $\mathrm{t} / \mathrm{dia}$ & \% de geração & $\mathrm{t} / \mathrm{dia}$ & $\%$ total \\
\hline Norte & 17.013 .559 & 8,5 & 12.692 & 6,4 & 8.149 & 64,2 & 4.543 & 35,8 \\
\hline Nordeste & 55.794 .707 & 27,7 & 43.894 & 22,1 & 28.206 & 64,3 & 15.688 & 35,7 \\
\hline Centro-Oeste & 14.993 .191 & 7,5 & 16.217 & 8,2 & 11.267 & 69,5 & 4.950 & 30,5 \\
\hline Sudeste & 84.465 .570 & 42,0 & 104.631 & 52,6 & 28.286 & 27,0 & 76.345 & 73,0 \\
\hline Sul & 28.795 .762 & 14,3 & 21.316 & 10,7 & 6.211 & 29,1 & 15.105 & 70,9 \\
\hline Brasil & 201.062 .789 & 100,0 & 198.750 & 100,0 & 82.119 & 41,3 & 116.631 & 58,7 \\
\hline
\end{tabular}

Fonte: adaptado de ABRELPE (2015) e IBGE (2010). 


\section{Projetos para geração de energia elétrica e biometano}

No Brasil, até o ano de 2016, foram registrados 30 projetos com potencial de gerar juntos 286,04 MW de energia elétrica, sendo que o primeiro ocorreu em 2004, no aterro sanitário Nova Gerar, em Nova Iguaçu (RJ). Estão localizados principalmente na região sudeste (20 projetos) e são responsáveis por $72 \%$ do total do potencial estimado (206,2 MW). Para a geração de biometano, existe somente o projeto do antigo lixão de Gramacho, em Duque de Caxias (RJ). As distribuições da quantidade e do potencial dos projetos nas regiões são representadas na Figura 2.

Dentre os projetos registrados para geração de energia elétrica, somente sete foram implementados, os quais juntos geram 56,1 MW: Centrais de Tratamento de Resíduos Sólidos (CTRS) BR-040 e Uberlândia I/II, em Minas Gerais; Bandeirantes, Sítio São João e Guatapará, em São Paulo; e Canhanduba, em Santa Catarina. No entanto, somente três obtiveram CER, conforme mostra a Tabela 2.

\section{Projetos de queima do biogás em flare(s)} enclausurado(s) com possibilidade futura de geração de energia elétrica ou biometano

No período de 2003 a 2016, foram registrados oito projetos com o objetivo inicial de coletar o biogás e depois queimá-lo em flare(s) enclausurados, evitando assim a emissão de metano na atmosfera. No futuro, esses projetos também poderão gerar energia elétrica ou biometano, que dependerá da concentração e qualidade de biogás coletado (Tabela 3).

\section{Projetos de queima do biogás em flare(s) enclausurado(s)}

Entre 2006 e 2012, verifica-se o registro de 20 projetos voltados à captura e à queima de biogás em flare(s) enclausurado(s), sendo que 13 obtiveram CER. Estão localizados principalmente na Região Sudeste
(13 projetos), e o restante nas Regiões Sul (4), Nordeste (2) e Norte (1), conforme mostra a Figura 3.

Os projetos que foram registrados visando à captura e à queima do biogás em flares estão relacionados na Tabela 4 .

\section{USINAS TERMELÉTRICAS IMPLANTADAS NO BRASIL QUE APROVEITAM O BIOGÁS PARA GERAÇÃO DE ENERGIA ELÉTRICA}

A pesquisa realizada no presente trabalho mostra que, no Brasil, entre os anos de 2004 e 2015, foram implantadas nove usinas termelétricas que aproveitam o biogás dos aterros de resíduos que geram 86,3 MW de energia elétrica (potência total instalada), conforme mostram a Figura 4 e a Tabela 5.

\section{Usinas termelétricas na Região Sudeste}

$\mathrm{Na}$ Região Sudeste, até o ano de 2015, foram implantadas, nos Estados de Minas Gerais e São Paulo, seis usinas termelétricas, que totalizam a potência instalada de 57,1 MW de energia elétrica. Com exceção da Usina Valor Gás, em Juiz de Fora (MG), as demais são participantes dos projetos do MDL, sendo que três delas já obtiveram CRE (CTRS BR-040, em Minas Gerais, e São João e Bandeirantes, em São Paulo) (Tabelas 2 e 5).

\section{Usina termoelétrica de biogás da Central de Tratamento de Resíduos Sólidos da BR-04O, em Belo Horizonte (MG)}

A usina funciona desde 2011, sob responsabilidade do Consórcio Horizonte ASJA, utilizando quatro motores geradores (1,4 MW cada), totalizando a potência de 5,7 MW. Em 2015, teve um motor desativado, passando a produzir 4,3 MW de energia elétrica (UNFCCC, 2015), e foi injetada na rede da Companhia Energética de Minas Gerais
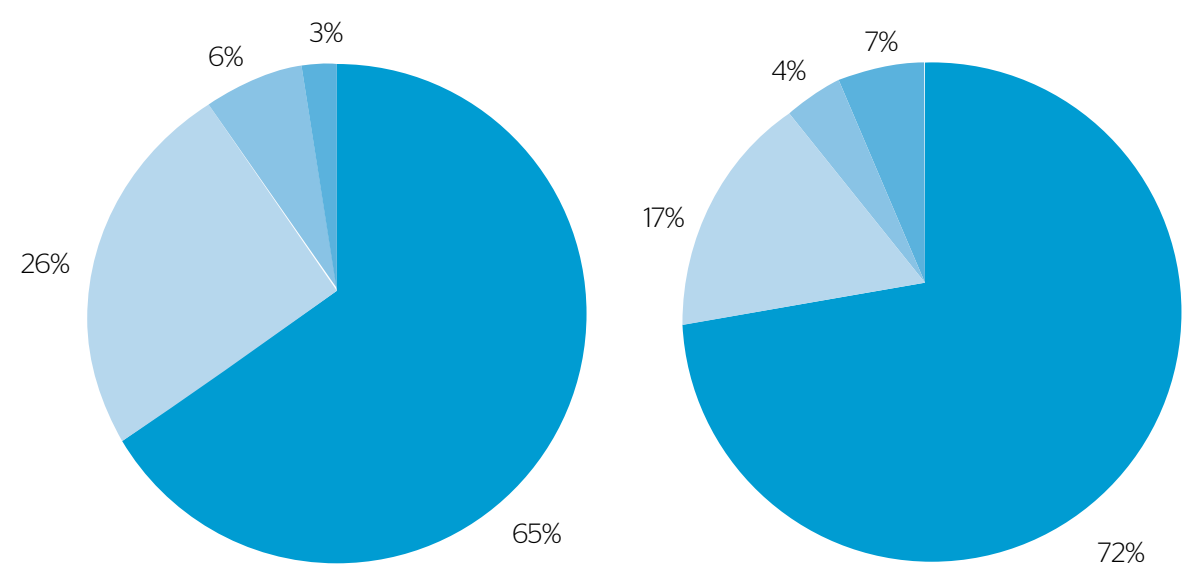

Norte

Sudeste

Sul

Nordeste

Figura 2 - Projetos registrados no Mecanismo de Desenvolvimento Limpo para geração de energia elétrica e biometano: (A) relação da distribuição da quantidade de projetos (\%); (B) potencial de geração de energia (\%). 
Tabela 2 - Relação dos projetos registrados no Mecanismo de Desenvolvimento Limpo visando à captura do biogás para geração de energia elétrica e biometano.

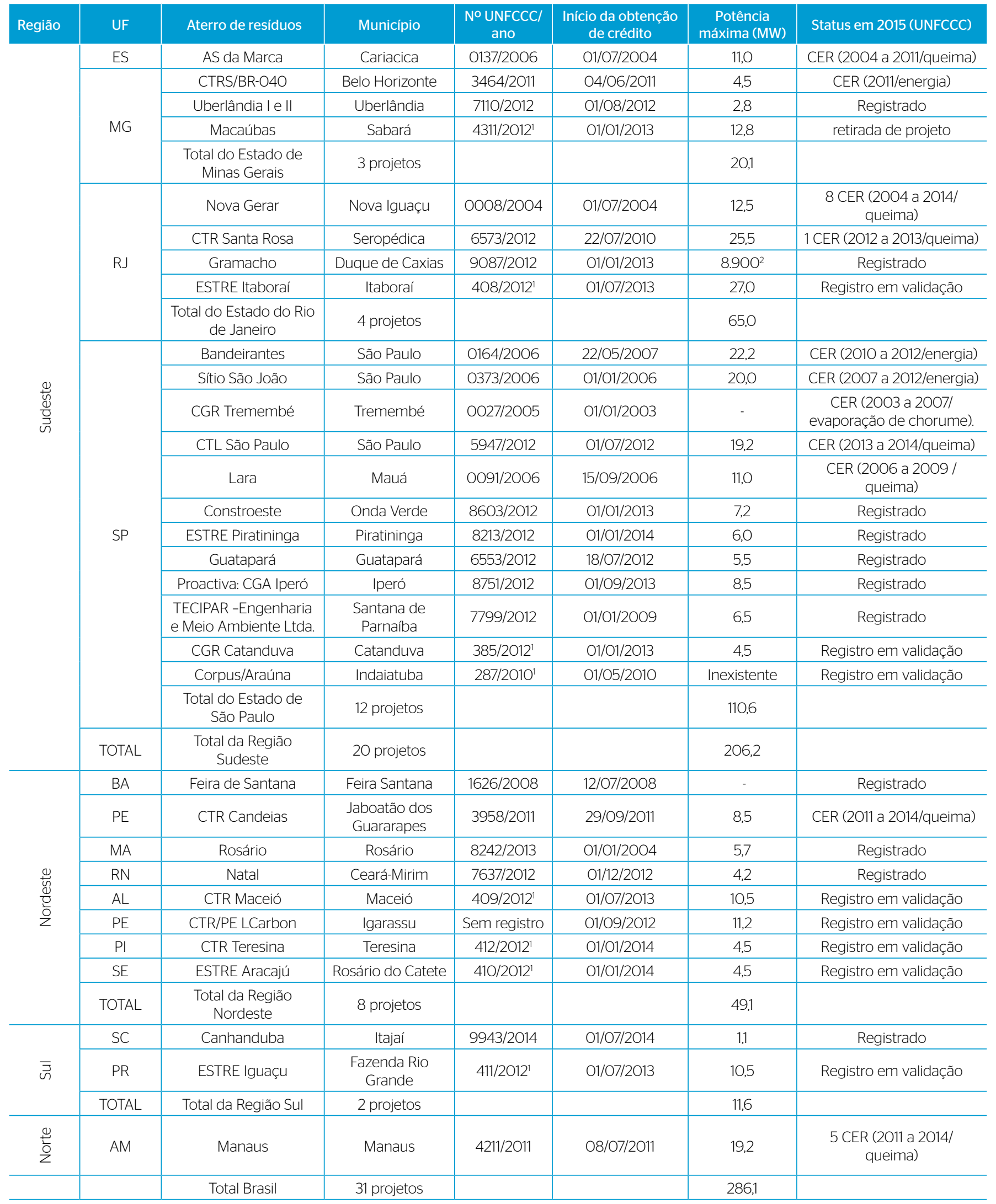

Fonte: Brasil (2015); UNFCCC (2015).

UNFCC: United Nations Framework Convention on Climate Change; AS: aterro sanitário; CER: Certificado de Redução de Emissão; CTRS: Central de Tratamento de Resíduos Sólidos; CTR: Central de Tratamento de Resíduos; CGR: Central de Gerenciamento de Resíduos; CTL: Central de Tratamento de Resíduos Leste; CGA: Centro de Gerenciamento Ambiental; ${ }^{1}$ registro MCTIC (Ministério da Ciência, Tecnologia, Inovações e Comunicações; ${ }^{2}$ unidade do potencial de geração de biometano ( $\left(\mathrm{Nm}^{3} / \mathrm{h}\right)$. 
(NARUC, 2012). O custo de implantação foi de 4,5 milhões de euros ( $\mathrm{R} \$ 15,5$ milhões, $€=\mathrm{R} \$ 3,44)$ (FEAM, 2014).

Ela explora o biogás do aterro da CTRS/BR-040, que foi operado de forma inadequada entre 1975 e 1994 (no início, como lixão e, depois, como aterro controlado) e, posteriormente, de 1995 a 2007, como aterro sanitário (NARUC, 2012), acumulando cerca de 24 milhões de metros cúbicos de RSU (FEAM, 2014).

\section{Usina termoelétrica do aterro}

\section{sanitário de Uberlândia, Uberlândia (MG)}

A usina entrou em funcionamento em 2012, sob responsabilidade da Energás Geração de Energia. Utiliza dois motores geradores, que produzem ambos 2,8 MW de energia elétrica, a qual é injetada na rede da Companhia Energética de Minas Gerais (CEMIG) (UNFCCC, 2015). O custo de implantação é estimado em 10,8 milhões de euros (R\$37,2 milhões, $€=\mathrm{R} \$ 3,44)$ (FEAM, 2014). Ela explora o biogás produzido nos aterros de Uberlândia I e II. O primeiro foi desativado em 2010, armazenando 2,1 milhões de toneladas de RSU. Em 2010, a disposição dos resíduos foi transferida para o segundo, que tem capacidade para dispor 4,5 milhões de metros cúbicos de RSU, em 18 anos (BRASIL, 2015). Dispõe diariamente 600 t/dia de RSU (FEAM, 2009).

\section{Usina termelétrica ValorGás, Juiz de Fora (MG)}

A usina foi implantada em 2013, em parceria com a ENC Power, do Grupo ENC Energy (ANEEL, 2015b). Utiliza um motor gerador, que produz 1,43 MW de energia. Há previsão de ampliação para 4,28 MW até 2022 (FEAM, 2014). Ela explora o biogás produzido no aterro sanitário da Central de Tratamento de Resíduos (CTR) da Zona da Mata, que funciona desde 2010, atendendo diariamente cerca de $851 \mathrm{mil}$ habitantes. Foi projetado para dispor 3,9 milhões de metros cúbicos de RSU, em 25 anos (Juiz de Fora, 2013).

\section{Usina termelétrica Bandeirantes, São Paulo (SP)}

A usina funciona desde 2004, sob responsabilidade da Biogás Energia Ambiental (Silva, 2006). Foi a primeira termelétrica nacional produtora de energia elétrica a partir do biogás gerado por RSU, em escala comercial. Possui 24 grupos geradores Caterpillar de $925 \mathrm{~kW}$ cada, que proporcionam 22,2 MW de energia elétrica, a qual é injetada na rede da AES Eletropaulo, sendo utilizada nas agências do Itaú Unibanco. Para a sua implantação, foram investidos R 48 milhões (UNFCCC, 2015). Ela utiliza o biogás produzido no aterro sanitário Bandeirantes, que funcionou de 1979 a 2007, dispondo cerca de 7.500 t/dia de RSU. Ocupa uma área de 140 hectares, com taludes de 110 metros de altura (NARUC, 2012). Armazenou cerca de 35 milhões de toneladas de resíduos (Pedott \& Aguiar, 2014).

\section{Usina termelétrica a biogás do Aterro Sítio São João, São Paulo (SP)}

A usina funciona desde 2008, sob responsabilidade da São João Energia Ambiental S.A. É operada por 14 motores geradores

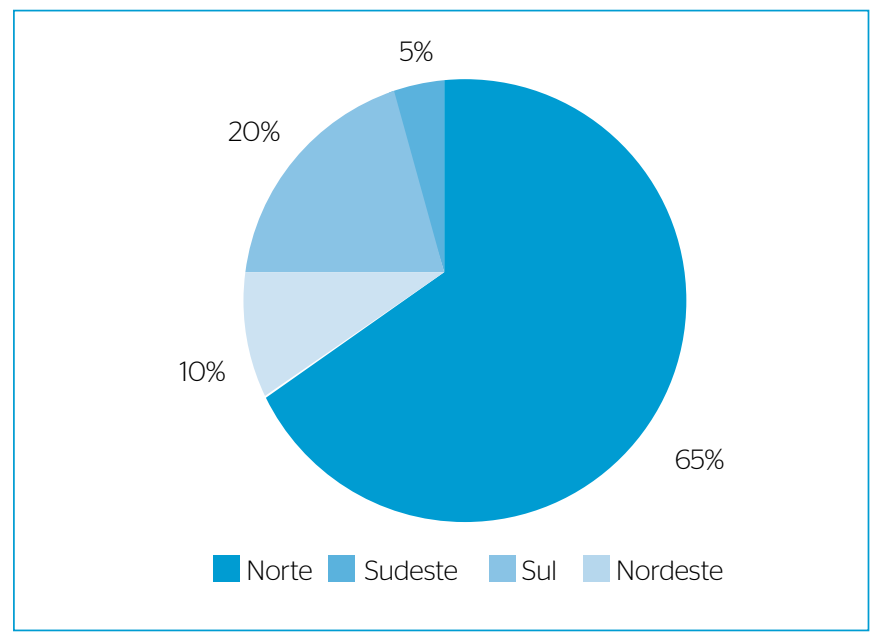

Figura 3 - Distribuição (\%) dos projetos de queima de biogás nas regiões do Brasil.

Tabela 3 - Relação dos projetos do Mecanismo de Desenvolvimento Limpo visando ao aproveitamento da queima do biogás, com possibilidade futura para geração de energia elétrica e biometano.

\begin{tabular}{|c|c|c|c|c|c|c|}
\hline REGIÃO & UF & Aterro de resíduos & Município & Registro UNFCCC/ ano & Início da obtenção de crédito & Status em 2015 (UNFCCC) \\
\hline \multirow{2}{*}{ Sudeste } & RJ & $\begin{array}{l}\text { CTRS Bob } \\
\text { Ambiental }\end{array}$ & Belford Roxo & $9295 / 2012$ & 01/07/2013 & Registrado \\
\hline & SP & CTR Caieiras & Caieiras & $0171 / 2006$ & 31/03/2006 & CER (2006 a 2014/queima) \\
\hline Nordeste & $\mathrm{BA}$ & Vega Bahia & Lauro de Freitas & $0052 / 2005$ & $01 / 01 / 2004$ & CER (2004 a 2006/queima) \\
\hline \multirow{3}{*}{ Sul } & \multirow{3}{*}{ RS } & CTR Caturrita & Santa Maria & $9302 / 2013$ & 01/07/2013 & Registrado \\
\hline & & ITVR São Leopoldo & São Leopoldo & $9290 / 2012$ & $01 / 07 / 2013$ & Registrado \\
\hline & & Rio Grande & Rio Grande & $9300 / 2013$ & $01 / 07 / 2013$ & Registrado \\
\hline \multirow{2}{*}{ Norte } & PA & CPTR Marituba & Marituba & $9298 / 2013$ & $01 / 07 / 2013$ & Registrado \\
\hline & PA & CPTR Puxinanã & Puxinanã & Sem registro & 01/07/2013 & Registro cancelado \\
\hline
\end{tabular}

Fonte: Brasil (2015); UNFCCC (2015).

UNFCC: United Nations Framework Convention on Climate Change; CTRS: Central de Tratamento de Resíduos Sólidos; CTR: Central de Tratamento de Resíduos; CER:

Certificado de Redução de Emissão; ITVR: Indústria de Tratamento e Valorização dos Resíduos; CPTR: Central de Processamento e Tratamento de Resíduos. 
(1,6 MW cada), que produzem 22,4 MW de energia elétrica, a qual é enviada à rede da AES Eletropaulo (UNFCCC, 2015). O investimento para a implantação do sistema foi de R\$ 64 milhões (CD4CDM, 2013). Ela explora o biogás produzido no aterro sanitário Sítio São João, que funcionou de 1992 a 2007, recebendo em média 6.000 t/dia de RSU (SANTO, 2013). Acumulou 27,9 milhões toneladas de resíduos, em taludes que atingiram até 150 metros de altura (São Paulo, 2008).

\section{Usina termelétrica de Guatapará, Guatapará (SP)}

A usina funciona desde agosto de 2014, sob responsabilidade da Estre Energia Renovável (AGÊNCIA ENVOLVERDE, JORNALISMO E SUSTENTABILIDADE, 2014). Produz 4,2 MW de energia elétrica, que abastece a subestação de Pradópolis (SP), da Companhia Piratininga de Força e Luz (CPFL), com custo de implantação na ordem de R\$ 15 milhões (TURIONI, 2014). Utiliza o biogás gerado no aterro sanitário do Centro de Gerenciamento de Resíduos (CGR) Guatapará, que é operado desde 2008, em uma área de 968 mil metros quadrados. Atende diariamente cerca de 871 mil habitantes e foi projetado para armazenar 10,5 milhões de toneladas de RSU (BRASIL, 2015). O aterro possui licença ambiental para dispor até $3.000 \mathrm{t} / \mathrm{dia}$ (CETESB, 2009).

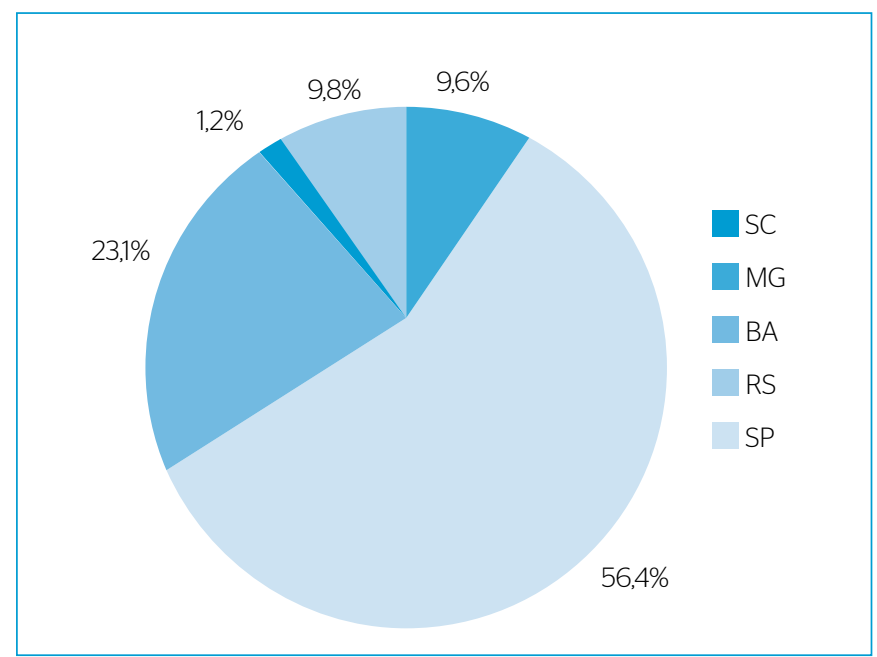

Figura 4 - Relação da distribuição (\%) da energia elétrica gerada nas usinas termelétricas implantadas no país.

Tabela 4 - Relação dos projetos do Mecanismo de Desenvolvimento Limpo visando à captura e à queima do biogás em flares.

\begin{tabular}{|c|c|c|c|c|c|c|}
\hline Região & UF & Aterro de resíduos & Município & $\begin{array}{l}\text { Registro UNFCCC } \\
\text { (ano) }\end{array}$ & Previsão da obtenção de crédito & Status (UNFCCC) \\
\hline \multirow{9}{*}{ Sudeste } & ES & CTR VV & Vila Velha & $1491 / 2008$ & 28/05/2008 & CER (2008/queima) \\
\hline & SP & Anaconda & Santa Isabel & $0226 / 2006$ & 15/01/2007 & CER (2007 a 2010/queima) \\
\hline & SP & Alto Tietê & Itaquaquecetuba & $1636 / 2008$ & 25/09/2008 & CER (2008 a 2010) rejeitada \\
\hline & SP & Embralixo/Araúna & Bragança Paulista & $1179 / 2007$ & 01/01/2008 & CER (2008 a 2010/queima) \\
\hline & SP & ESTRE Itapevi & Itapevi & 0911/2007 & 17/08/2007 & CER (2007 a 2012/queima) \\
\hline & SP & Paulinía & Paulínia & 0165/2006 & 14/09/2006 & CER (2006 a 2013/queima) \\
\hline & SP & $\begin{array}{c}\text { Terrestre } \\
\text { Ambiental }\end{array}$ & Santos & $1133 / 2008$ & 06/05/2008 & CER (2008 a 2009/queima) \\
\hline & $\mathrm{SP}$ & UTGR Jambeiro & Jambeiro & $8011 / 2012$ & 01/01/2014 & Registrado \\
\hline & SP & Araúna & Marília & $283 / 2010$ & 01/01/2009 & Registro em validação \\
\hline \multirow{2}{*}{ Nordeste } & BA & Canabrava & Salvador & 0893/2007 & 08/04/2007 & CER (2007/queima) \\
\hline & PB & PROBIOGÁS & João Pessoa & $1165 / 2008$ & 27/11/2008 & CER (2008 a 2011/queima) \\
\hline \multirow{4}{*}{ Sul } & RS & Recreio SIL & Minas do Leão & 0648/2006 & 01/12/2007 & CER (2007 a 2013/queima) \\
\hline & SC & Tijuquinhas & Biguaçu & $1506 / 2008$ & 29/10/2008 & CER (2008 a 2013/queima) \\
\hline & SC & SANTECH & Içara & 1908/2009 & 18/02/2010 & Registrado \\
\hline & SC & Laguna & Laguna & Sem registro & $01 / 01 / 2010$ & Registro em validação \\
\hline
\end{tabular}

Fonte: Brasil (2015); UNFCCC (2015).

UNFCC: United Nations Framework Convention on Climate Change; CTR: Central de Tratamento de Resíduos; CER: Certificado de Redução de Emissão; CDR: Centro de Disposição de Resíduos; UTGR: Unidade de Tratamento e Gestão de Resíduos Sólidos. 


\section{Usinas termelétricas nas Regiões Nordeste e Sul}

Nas Regiões Nordeste e Sul, foram implantadas três usinas termelétricas, sendo que todas participam do MDL. A Usina Termelétrica de Itajaí, em Santa Catarina, foi registrada com o objetivo de gerar energia elétrica. A Usina Termoverde Salvador, na Bahia, e a Usina Biotérmica Recreio, no Rio Grande do Sul, foram registradas somente para queima do biogás em flares (Tabelas 2 e 4).

\section{Usina Termoverde Salvador, Salvador (BA)}

A usina Termoverde Salvador, operada pelo Grupo Solvi, foi a primeira a ser implantada na Região Nordeste, em janeiro de 2011. Possui potência instalada de 19,73 MW, que é proporcionada por 19 motores de $1,04 \mathrm{MW}$ cada. A energia elétrica é enviada à rede elétrica da Companhia de Energia Elétrica da Bahia (COELBA) (NARUC, 2012), com custo de implantação estimado em R\$ 50 milhões (SOLVI SOLUÇÕES PARA A VIDA, 2011). Ela explora o biogás gerado no aterro sanitário Metropolitano Centro, que funciona desde 1997, em uma área de 600 mil metros quadrados, atendendo cerca de três milhões de habitantes, que geram, em média, $2.500 \mathrm{t} /$ dia de RSU, sendo projetado para armazenar 18 milhões de toneladas de resíduos (NARUC, 2012).

\section{Usina termelétrica Itajaí Biogás e Energia S.A., Canhanduba (SC)}

A usina termelétrica é operada desde 2014 pela empresa Itajaí Biogás e Energia S.A. Produz $1 \mathrm{MW}$ de energia elétrica, a qual é enviada às Centrais
Elétricas de Santa Catarina (CELESC), com custo de implantação de R \$ 7,5 milhões (FLORIPANEWS, 2014). Ela explora o biogás do aterro sanitário de Canhanduba, que funciona desde 2006, dispondo cerca de 300 t/dia de RSU, com previsão para ser encerrado em 2027 (AMFRI, 2014).

Usina termelétrica Biotérmica Recreio, Minas do Leão (RS) A usina Biotérmica Recreio, operada pelo Grupo Solvi e Copelmi Mineração, foi inaugurada em 2015 (MUYLAERT, 2000). Possui seis motores geradores com potência de 1,426 MW cada, que produz 8,5 MW de energia elétrica, a qual é encaminhada à Subestação Elevadora Areal, da Companhia Estadual de Distribuição de Energia Elétrica (CEEE-D). A implantação custou R 28.737.130 (BRASIL, 2014). Ela aproveita o biogás do aterro sanitário da Central de Resíduos do Recreio (CRR), que ocupa uma cava remanescente de mineração de carvão, com 73 hectares de área, 51 metros de profundidade e capacidade para dispor 23 milhões de toneladas de RSU, em 23 anos (CRVR, 2013). Em 2014, atendia cerca de 4,0 milhões de habitantes (34\% da população gaúcha) de 140 municípios, totalizando o recebimento de 90 mil toneladas/mês de RSU.

\section{USINAS DE APROVEITAMENTO DO BIOGÁS PARA GERAÇÃO DE BIOMETANO IMPLANTADAS NO BRASIL}

No Brasil, a primeira iniciativa de aproveitamento de biogás para produzir biometano ocorreu na década de 1970, na cidade do Rio

Tabela 5 - Usinas termelétricas implantadas para geração de energia elétrica.

\begin{tabular}{|c|c|c|c|c|c|c|c|}
\hline Região & UF & Usina termelétrica & Município & $\begin{array}{l}\text { Início da } \\
\text { operação }\end{array}$ & $\begin{array}{c}\text { Potência } \\
\text { explorada (MW) }\end{array}$ & $\begin{array}{l}\text { Custo (milhões } \\
\text { de } R \$ \text { ) }\end{array}$ & Envio da energia \\
\hline \multirow{7}{*}{ Sudeste } & & CTR BR-04O & Belo Horizonte & 05/2011 & 4,3 & 19,8 & CEMIG \\
\hline & MG & Valor Gás & Juiz de Fora & $08 / 2013$ & 1,4 & Desconhecido. & Desconhecido \\
\hline & Total & Minas Gerais & & & 8,5 & 67,3 & \\
\hline & SP & Biogás Aterro São João & São Paulo & 06/2007 & 22,4 & 64 & AES ELETROPAULO \\
\hline & & Guatapará & Guatapará & 08/2014 & 4,2 & 15 & CPFL (subestação Pradópolis) \\
\hline & Total & São Paulo & & & 48,8 & 127 & \\
\hline & Total & Sudeste & 6 projetos & & 57,1 & 194,3 & \\
\hline \multirow[t]{2}{*}{ Nordeste } & $\mathrm{BA}$ & Termoverde Salvador & Salvador & $01 / 2011$ & 19,7 & 50 & COELBA \\
\hline & & Total do Brasil & & & 86,3 & 280,5 & \\
\hline
\end{tabular}

Fonte: AMFRI (2014); ANEEL (2015a); Agência Envolverde, Jornalismo e Sustentabilidade (2014); FEAM (2014); GAUCHAZH (2014); FloripaNews (2014); Turioni (2014); Brasil (2014; 2015); Muylaert (2000); NARUC (2012); Santo (2013); Silva (2006); Solvi Soluções para a Vida (2011).

CTR: Central de Tratamento de Resíduos; CEMIG: Companhia Energética de Minas Gerais; CPFL: Companhia Piratininga de Força e Luz; CELESC: Centrais Elétricas de Santa Catarina S.A.; COELBA: Companhia de Eletricidade do Estado da Bahia). 
de Janeiro, no antigo lixão do Caju, que foi operado de 1935 a 1977 (42 anos), acumulando cerca de 30 milhões de metros cúbicos de RSU em uma área de um milhão de metros quadrados. O sistema foi implantado pela Companhia Municipal de Limpeza Urbana do Estado do Rio de Janeiro (COMLURB), que recuperou cerca de 20 milhões de metros cúbicos de biogás, injetando-o na rede de gás natural da Companhia Estadual de Gás do Rio de Janeiro (CEG). Em 1980, passou a abastecer parte da frota da COMLURB (MUYLAERT, 2000).

Posteriormente, somente em 2014, surgiram duas outras iniciativas para produzir biometano, também localizadas no Estado do Rio de Janeiro, provavelmente em decorrência da Política Estadual de Gás Natural Renovável (GNR), que obriga as concessionárias de distribuição de gás canalizado a adquirirem, de forma compulsória, todo o GNR produzido no Estado, até o limite de $10 \%$ do volume de gás natural convencional (AGENERSA, 2012). A primeira a entrar em operação foi a Usina de Gás Verde Gramacho e, em seguida, a Usina de Tratamento de Biogás Dois Arcos, conforme mostra a Tabela 6 .

A Usina de Gás Verde Gramacho, operada pela Gás Verde S.A., iniciou suas atividades em maio de 2014, enviando diariamente cerca de 49 mil metros cúbicos de biometano à Refinaria Duque de Caxias (REDUC), da Petrobras. O investimento para a implantação do sistema de purificação do biogás e transporte foi de R\$ 90 milhões (Petronotícias, 2014). Ela aproveita o biogás gerado no aterro Metropolitano de Gramacho, considerado o maior aterro de resíduos da América Latina, que funcionou de 1978 a 2012, acumulando 80 milhões de toneladas de RSU em uma área de um milhão de metros quadrados de manguezal (RIO DE JANEIRO, 2014).

A Usina de Tratamento de Biogás Dois Arcos, operada pelas empresas OSAFI e Ecometano, produz em média oito mil metros cúbicos diários de biometano, que são enviados à Rede de Supermercados Guanabara, em Itaguaí (RJ). Há previsão de ampliação do sistema, que proporcionará a produção de 15 mil metros cúbicos (SBERA, 2015), os quais serão injetados na rede da Companhia Estadual de Gás do Rio de Janeiro (CEG-Rio) (EcoDebate, 2015). Ela explora o biogás gerado no aterro sanitário Dois Arcos, que funciona desde 2008, e dispõe em média 700 t/dia de RSU (FEEMA, 2009).

\section{PROJETOS IMPLANTADOS QUE UTILIZAM BIOGÁS PARA EVAPORAÇÃO DE LIXIVIADO}

Os projetos que utilizam o biogás para a evaporação de lixiviado consistem na captura e queima do biogás, o qual, devido a sua alta temperatura, possibilita a evaporação da água (oxidação térmica) e a remoção das substâncias voláteis contidas no lixiviado gerado nos aterros sanitários.

O primeiro projeto foi instalado em 2001, no aterro sanitário de Tremembé (SP), que possui capacidade para tratar diariamente até 19 metros cúbicos de lixiviado (BRASIL, 2015). Posteriormente, no Rio Grande do Sul, foram implantados dois projetos, que tratam, cada um, 24 metros cúbicos diários do lixiviado. O primeiro, em 2008, no aterro sanitário da CTR da Caturrita, em Santa Maria, e o segundo, em 2011, no aterro da CTR Giruá, em Giruá (Rosa, 2014).

\section{POTENCIAL DE GERAÇÃO DE ENERGIA ELÉTRICA NOS ATERROS DE RESÍDUOS NO BRASIL}

Os principais estudos realizados no País sobre o potencial de geração de energia elétrica nos aterros de resíduos foram impulsionados pela criação do MDL, registrando projetos que visam reduzir os GEE

O primeiro, denominado de Estudo do potencial da geração de energia renovável proveniente dos aterros sanitários nas regiões metropolitanas e grandes cidades do Brasil, foi desenvolvido entre 2001 e 2004, por meio do Convênio Fundação de Estudos Agrários Luiz de Queiroz (FEALQ) e Ministério do Meio Ambiente. Envolveu 108 municípios com população superior a 200 mil habitantes, sendo que 92 são integrantes de regiões metropolitanas. O potencial foi estimado utilizando o programa Landfill Gas Emissions Model (LANDGEM), desenvolvido pela Environmental Protection Agency (EPA) para avaliar as emissões dos GEE (BRASIL, 2004). Esse projeto utiliza informações relativas aos RSU quanto a: composição (\% de matéria orgânica), volume diário disposto e idade de aterramento (ABRELPE, 2012). Para 2015, foi estimado o potencial máximo de 440 MW (denominado de "otimista”) (BRASIL, 2004), que deve ser reavaliado. O modelo adotado não considera as condições técnicas e operacionais dos aterros de resíduos, bem como envolveu somente os aterros de resíduos que atendiam a municípios de médio a grande porte (superior a $200 \mathrm{mil}$ habitantes), não incluindo as soluções

Tabela 6 - Usinas de aproveitamento do biogás para geração de biometano implantadas no Brasil.

\begin{tabular}{l|c|c|c|c|c|c} 
UF & Usinas de biometano & Municipio & Início da operação & $\begin{array}{c}\text { Volume produzido } \\
\left(\mathrm{m}^{3} / \text { dia) }\right.\end{array}$ & $\begin{array}{c}\text { Custo (milhões } \\
\text { de R\$) }\end{array}$ & Uso \\
\hline RJ & Verde Gramacho & Duque de Caxias & $05 / 14$ & 49.000 & 90 & REDUC \\
\hline RJ & Dois Arcos & São Pedro da Aldeia & $08 / 14$ & 8.000 & Desconhecido & Supermercados. Guanabara \\
\hline
\end{tabular}

Fonte: PetroNotícias (2014); SBERA (2015).

REDUC: Refinaria Duque de Caxias (Petrobras). 
compartilhadas de disposição de RSU em aterros sanitários localizados em cidades menores, comuns na atualidade.

Posteriormente, em 2007, o Ministério Ciência, Tecnologia, Inovações e Comunicações (MCTIC) publicou o Plano Nacional de Energia 2030, que estabelece, para os anos de 2020 e 2030, os potenciais de 1.700 e 2.600 MW, respectivamente (EPE, 2007). A projeção para 2020, fundamentada também em metodologia norte-americana, foi estimada em função do volume diário disposto (adotando a geração per capita de $0,54 \mathrm{~kg} / \mathrm{dia}$ ) e da composição dos RSU (47,5\% de matéria orgânica). No entanto, se considerarmos dados da ABRELPE (2015), esses valores correspondem a $1,07 \mathrm{~kg} / \mathrm{dia}$ e $52 \%$, respectivamente. A projeção para 2030 considerou o crescimento da economia nacional e a maior distribuição da renda entre a população brasileira e o consequente aumento da produção e alteração da composição dos RSU (EPE, 2007).

Nota-se que ambos os métodos norte-americanos adotados não consideram as características operacionais dos aterros de resíduos, que são essenciais à realidade nacional, visto que cerca de $42 \%$ dos RSU gerados no Brasil são dispostos de forma inadequada (lixões e aterros controlados).

A diferença significativa do potencial estimado entre o Plano Nacional de Energia para 2020 (1.700 MW) e do Ministério do Meio Ambiente (MMA) (440 MW) provavelmente está relacionada ao número elevado de habitantes considerado no primeiro caso, isto é, toda a população brasileira. No entanto, cerca de $94 \%$ dos municípios e $45 \%$ do contingente populacional estão concentrados em cidades que possuem população inferior a 100 mil habitantes, que dispõem seus RSU geralmente de forma inadequada, não favorecendo assim o aproveitamento energético do biogás desses aterros.

Finalmente, o Atlas Brasileiro de Emissões de GEE e Potencial Energético, publicado em 2012, indica o potencial total de $536 \mathrm{MW}$, correspondente à somatória dos potenciais dos projetos de MDL (254 MW) e da estimativa realizada pela ABRELPE (282 MW) (ABRELPE, 2012). Em ambos os casos, foi aplicada a metodologia do Intergovernmental Panel on Climate Change (IPCC), usualmente utilizada em estudos de inventários de emissões de GEE, que, dentre outros parâmetros, considera a quantidade e composição dos RSU, as médias anuais de precipitação e temperatura da área do aterro e a qualidade operacional dos aterros.

A Figura 5 apresenta os potenciais estimados de geração de energia elétrica estabelecidos pelos estudos realizados e descritos anteriormente.

Considerando as diferentes estimativas dos potenciais de geração de energia elétrica nos aterros de resíduos do País e a potência instalada de 86,3 MW nas 9 usinas termelétricas implantadas, têm-se basicamente dois cenários: um mais otimista e realista, no qual o país explora 16\% do seu potencial (ABRELPE, 2012), e outro mais pessimista, em que somente 5,1\% desse potencial é explorado (EPE, 2007), conforme se verifica na Figura 6.

\section{CONCLUSÕES}

O Brasil possui um potencial considerável de aproveitamento do biogás para geração de energia elétrica ou biometano em seus diversos aterros sanitários, se considerarmos o volume expressivo de RSU gerado (219 $\mathrm{mil} \mathrm{t}$ /dia) e a alta porcentagem de matéria orgânica (52\%) contida nestes. No entanto, o levantamento realizado no presente estudo mostra que esse potencial estimado ainda é controverso, provavelmente em decorrência do uso de metodologias de avaliação distintas, da utilização de dados desatualizados em relação à quantidade e à composição dos RSU e da indisponibilidade de informações técnicas e ambientais dos aterros de resíduos existentes.

Com exceção do método do IPCC, os demais utilizam informações válidas para avaliar o potencial dos aterros sanitários estadunidenses, não contemplando as condições operacionais e o clima dos locais de

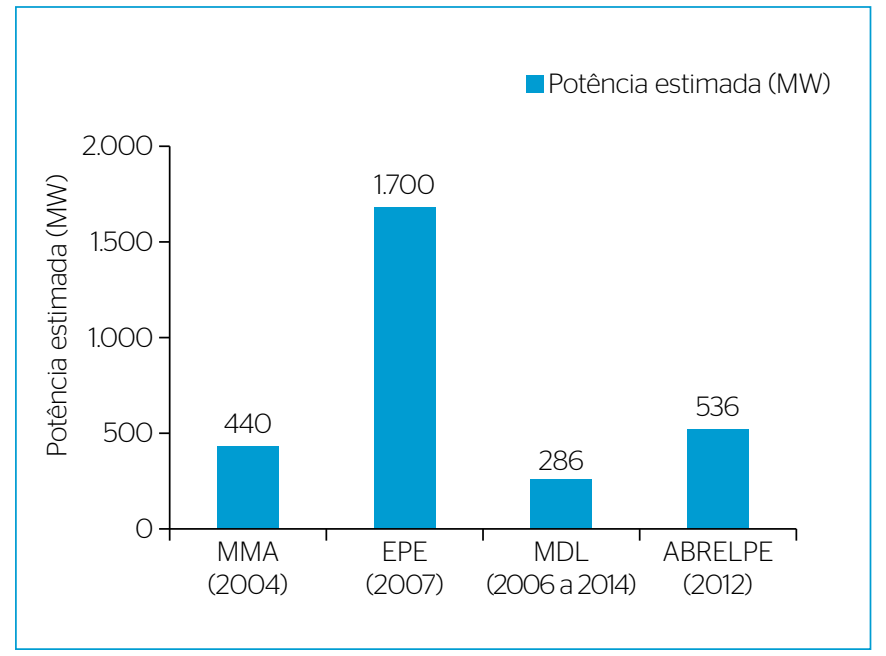

Figura 5 - Potenciais estimados de geração de energia elétrica através do aproveitamento de biogás nos aterros de resíduos do Brasil.

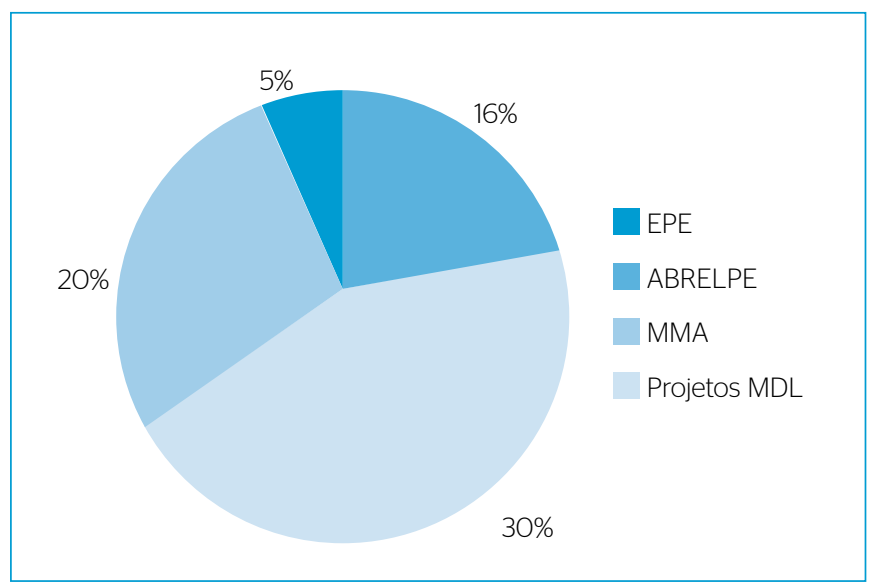

Figura 6 - Relação (\%) entre a energia elétrica gerada nas termelétricas implantadas no Brasil e o potencial estimado pela Associação Brasileira de Empresas de Limpeza Pública e Resíduos Especiais (ABRELPE) $x$ Projetos Mecanismo de Desenvolvimento Limpo (MDL) x Ministério do Meio Ambiente (MMA) x Empresa de Pesquisa Energética (EPE). 
disposição final dos resíduos, consideradas informações relevantes no caso dos aterros brasileiros.

Portanto, o país ainda não conhece o seu potencial de geração de energia elétrica por meio de seus recursos renováveis no caso específico da biomassa contida nos RSU e, consequentemente, aproveita pouco o biogás gerado nos seus aterros.

Por outro lado, o atual cenário das mudanças climáticas mostra a urgente necessidade de as autoridades nacionais colocarem em pauta a busca de soluções que visem diminuir a emissão dos GEE e a dependência da utilização de combustíveis fósseis e não renováveis, incentivando a exploração de fontes alternativas de energia renováveis, no caso o aproveitamento do biogás produzido nos diversos aterros de RSU do Brasil.

Para tal, é fundamental o conhecimento do potencial energético dos aterros de resíduos no País e ainda a concretização de incentivos fiscais e financeiros à criação de consórcios públicos para a disposição compartilhada dos RSU, principalmente entre municípios de pequeno porte (até 50 mil habitantes), a fim de proporcionar maior volume de resíduos aterrados e o consequente aproveitamento de biogás para geração de energia elétrica e biometano.

\section{FONTE DE FINANCIAMENTO}

Petrobras, Agência Nacional de Energia Elétrica.

\section{AGRADECIMENTOS}

Este trabalho foi desenvolvido com o apoio da Fundação Escola de Sociologia e Política de São Paulo (FESPSP) e financiado pela empresa Petróleo Brasileiro S.A. (Petrobras) por meio do projeto "Estudo da Geração em Ciclo Combinado a partir de Biogás e Resíduos Sólidos", integrante da Chamada 14 da Agência Nacional de Energia Elétrica (ANEEL), que se refere a Pesquisa \& Desenvolvimento Estratégico na área de biogás a partir de resíduos sólidos. Agradecemos aos relatores da Associação Brasileira de Engenharia Sanitária e Ambiental (ABES) pelas sugestões e revisões do manuscrito do presente artigo.

\section{REFERÊNCIAS}

AGÊNCIA ENVOLVERDE, JORNALISMO E SUSTENTABILIDADE. (2014) Nova usina de biogás transformará lixo de 20 municípios em energia. Agência Envolverde, Jornalismo e Sustentabilidade, São Paulo. Disponivel em: <http://www.envolverde.com.br/ambiente/nova-usinade-biogas-transformara-lixo-de-20-municipios-em-energia/>. Acesso em: 2015

AGÊNCIA REGULADORA DE ENERGIA E SANEAMENTO BÁSICO DO ESTADO DO RIO DE JANEIRO (AGENERSA). (2012) Lei no 6.361, de 19 de dezembro de 2012. Dispõe sobre a Política Estadual de Gás Natural Renovável GNR. Rio de Janeiro: AGENERSA. Disponível em: $<$ https://gov-ri.jusbrasil.com.br/legislacao/1033645/lei-6361-12>. Acesso em: maio 2015.

ASSOCIAÇÃO BRASILEIRA DE EMPRESAS DE LIMPEZA PÚBLICA E RESÍDUOS (ABRELPE). (2012) Atlas Brasileiro de Emissões de GEE e Potencial Energético na Destinação de Resíduos Sólidos. São Paulo: ABRELPE. $109 \mathrm{p}$

(2015) Panorama de Resíduos Sólidos, Brasil. São Paulo: ABRELPE.

ASSOCIAÇÃO DOS MUNICÍPIOS DA FOZ DO RIO ITAJAI (AMFRI). (2014) PMGIRS, Produto 4: Diagnóstico dos Resíduos Sólidos do Município: Itajaí,SC. Itajaí:AMFRI. Disponível em:<http://www2.aneel. gov.br/aplicacoes/capacidadebrasil/OperacaoCapacidadeBrasil. cfm>. Acesso em: jun. 2015.

AGÊNCIA NACIONAL DE ENERGIA ELÉTRICA (ANEEL). (2015a) Capacidade de geração do Brasil. Brasília: aneel. Disponível em: <http://www.aneel.gov.br/aplicacoes/capacidadebrasil/ CombustivelListaUsinas.asp?classe=Biomassa\&combustivel=1 9\&fase=3>. Acesso em: dez. 2015.

(2015b) Matriz de energia elétrica, Banco de Informações de Geração (BIG). Brasília: aneel. Disponível em: <http://www.aneel.gov. br/aplicacoes/capacidadebrasil/OperacaoCapacidadeBrasil.cfm>. Acesso em: nov. 2015

BARIN, A. (2012) Seleção de sistemas de geração de energia elétrica a partir de residuos sólidos urbanos: uma abordagem com a lógica difusa. Tese (Doutorado em Energia Elétrica) - Universidade Federal de Santa Maria, Santa Maria. Disponível em: <http://cascavel.ufsm.br/tede/ tde_busca/arquivo.php?codArquivo=4583>. Acesso em: mar. 2015.

BRASIL. (2002) Lei Federal no 10.438. Dispõe sobre a expansão da oferta de energia elétrica emergencial, cria o Programa de Incentivo às Fontes Alternativas de Energia Elétrica (Proinfa), e dá outras providências. Brasília. Disponível em: <www.planalto.gov.br/ ccivil_O3/leis/2002/L10438.htm>. Acesso em: abr. 2017.

(2004) Ministério do Meio Ambiente. Estudo do potencial da geração de energia renovável proveniente dos "aterros sanitários" nas regiões metropolitanas e grandes cidades do Brasil. Convênio FEALQ. Brasília: Ministério do Meio Ambiente. Disponível em: <https:// www.cepea.esalq.usp.br/br/documentos/texto/-aba-hrefcepeammaphpdestaque-estudo-do-potencial-da-geracao-de-energiarenovavel-proveniente-dos-aterros-sanitarios-nas-regioes-metropolitanas-e-grandes-cidades-do-brasil-a-b.aspx>. Acesso em: abr. 2015 
(2014) Ministério de Minas e Energia. Portaria no 200. Brasília: Ministério de Minas e Energia . Disponível em: <http://www.mme. gov.br/documents/10584/1154459/Portaria SPE n 200-2014. pdf/3O2feO21-15d1-4746-9758-d169c41cd12c>. Acesso em: jun. 2015.

(2015) Ministério da Ciência, Tecnologia e Inovação. Atividades de Projetos MDL Aprovados nos Termos da Resolução no 1. Brasília: Ministério da Ciência, Tecnologia e Inovação. Disponível em: < https://www.mctic.gov.br/mctic/opencms/ciencia/SEPED/ clima/mecanismo_de_desenvolvimento_limpo/Mecanismo_de_ Desenvolvimento_Limpo.html>. Acesso em: jun. 2015.

CENTER ON ENERGY, CLIMATE AND SUSTAINABLE DEVELOPMENT (CD4CDM). (2013) Pipeline overview. Estados Unidos: CD4CDM. Disponível em: <http://cdmpipeline.org/>. Acesso em: maio 2015

COMPANHIA AMBIENTAL DO ESTADO DE SÃO PAULO (CETESB). (2009) Inventário Estadual de Residuos Urbanos. São Paulo: CETESB. Disponível em: <http://autenticidade.cetesb.sp.gov. br/pdf/O2520002350117042009.pdf>. Acesso em: maio 2015.

COMPANHIA RIOGRANDENSE DE VALORIZAÇÃO DE RESÍDUOS (CRVR). (2013) Central de Tratamento de Resíduos de Giruá. Giruá: CRVR. Disponível em: <http://www.crvr.com.br/UnidadeGirua. html>. Acesso em: jun. 2015.

ECODEBATE. (2015) RJ recebe o primeiro ônibus movido a biometano gerado a partir de lixo. EcoDebate, Rio de Janeiro. Disponível em: <http://www.ecodebate.com.br/2015/03/13/rjrecebe-o-primeiro-onibus-movido-a-biometano-gerado-a-partir-delixo/>. Acesso em: maio 2015.

ECODESENVOLVIMENTO. (2015) Gases de efeito estufa bateram recordes em 2014, alerta relatório. Ecodesenvo/vimento, Salvador. Disponível em: <http://www.ecodesenvolvimento.org/ posts/2015/julho/gases-de-efeito-estufa-bateram-recordes-em2014?tag=clima>. Acesso em: ago. 2015.

EMPRESA DE PESQUISA ENERGÉTICA (EPE). (2007) Plano Nacional de Energia 2030. Brasília: Ministério de Minas e Energia. Disponível em: <http://www.epe.gov.br/pt/publicacoes-dadosabertos/publicacoes/Plano-Nacional-de-Energia-PNE-2030>. Acesso em: 2015.

(2015) Balanço Energético Nacional 2015, Ano Base 2014. Brasília: Ministério de Minas e Energia. Disponível em: <http://www. epe.gov.br/pt/publicacoes-dados-abertos/publicacoes/BalancoEnergetico-Nacional-2015>. Acesso em: out. 2015.

FLORIPANEWS. (2014) Transformação de lixo em Energia elétrica já é realidade em SC. FloripaNews, Florianópolis. Disponível em: <http://www.floripanews.com.br/noticia/5200-transformacao-delixo-em-energia-eletrica-ja-e-realidade-em-sc>. Acesso em: abr. 2015.

FUNDAÇÃO ESTADUAL DE MEIO AMBIENTE (FEAM). (2009) Análise de pré-viabilidade técnica, econômica e ambiental da implantação de um sistema de aproveitamento energético de biogás em um aterro sanitário existente no estado de Minas Gerais. Relatório 1. Belo Horizonte: FEAM. Disponível em: <http://www. feam.br/images/stories/fean/parte_1.pdf>. Acesso em: abr. 2017.
(2014) Potencial de energias renováveis-biomassa, resíduos e hidroeletricidade. Belo Horizonte: FEAM. v. 2. Disponível em: <http://www.feam.br/images/stories/EnergiaMudancasClimaticas/ Publicacoes2014/pemc_potencial_er_vol_ii_v1.0_15_04_2014.pdf>. Acesso em: jun. 2015.

FUNDAÇÃO ESTADUAL DE ENGENHARIA DO MEIO AMBIENTE (FEEMA). (2009) Licença de Operação no FEO13200. Rio de Janeiro: FEEMA. Disponível em: <http://www.doisarcos.com.br/ doisarcos_lo.pdf>. Acesso em: abr. 2015.

GAUCHAZH Últimas Notícias. (2014). Maior aterro sanitário do sul do País recebe 90 mil toneladas por mês de lixo. Porto Alegre. Disponível em: https://gauchazh.clicrbs.com.br/noticia/2014/10/ maior-aterro-sanitario-do-sul-do-pais-recebe-90-mil-toneladaspor-mes-de-lixo-cj5vqd3njOpaOxbjO1kttsb17.html. Acesso em: abr. 2016.

GOVERNO LOCAIS PELA SUSTENTABILIDADE (ICLEI). (2OO9) Manual para aproveitamento de biogás, aterros sanitários. São Paulo: ICLEl. v. 1. Disponível em: <www.resol.com.br/cartilha12/ manual_iclei_brazil.pdf>. Acesso em: abr. 2017.

INSTITUTO BRASILEIRO DE GEOGRAFIA E ESTATISTICA (IBGE). (2010). Censo Demográfico 2010. Rio de Janeiro: IBGE.

(2011) Sinopse do Censo Demográfico 2010. Rio de Janeiro: IBGE.

INTERGOVERNAMENTAL PANEL ON CLIMATE CHANGE (IPCC). (1996) Guia para inventários nacionais de gases de efeito estufa. Módulo 6: Lixo. Estados Unidos: IPCC. v. 2. Disponível em: <http://www.ipcc-nggip.iges.or.jp/public/gl/ invs6.html>. Acesso em: jun. 2015.

. (2014) Climate Change 2014. Synthesis Report. Contribution of Working Groups I, II and III to the Fifth Assessment Report of the Intergovernmental Panel on Climate Change. Genebra: IPCC. Disponível em: < https://www.ipcc.ch/report/ar5/syr/>. Acesso em: out. 2017.

JUIZ DE FORA. (2013) Plano de Saneamento Básico de Juiz de Fora, MG. Etapa I, Diagnóstico. Juiz de Fora: Prefeitura. Disponível em: <http://www.planodesaneamento.pjf.mg.gov.br/pdf/apostila conferencia_i.pdf>. Acesso em: jun. 2015.

MUYLAERT, M.S. (2000) Consumo de energia e aquecimento do planeta. Análise do Mecanismo de Desenvolvimento Limpo MDL do Protocolo de Quioto - Estudos de Caso. Rio de Janeiro: Editora da Coppe.

NATIONAL ASSOCIATION OF REGULATORY UTILITY COMMISSIONERS (NARUC). (2012) Aproveitamento de gás de aterro sanitário no Brasil e sua regulação. Washington, D.C.: NARUC.

PECORA, V.G.; VELAZZQUEZ, S.M.S.G.; COELHO, S.T. (2010) Aproveitamento de biogás proveniente de aterro sanitário para geração de energia elétrica em São Paulo. In: CONGRESSO BRASILEIRO DE PLANEJAMENTO ENERGÉTICO, 7., São Paulo. Anais... São Paulo: USP, p. 1249-1261. 
PEDOTT, J.G.J.; AGUIAR, A.O. (2014) Biogás em aterros sanitários: comparando a geração estimada com a quantidade verificada em projetos de Mecanismo de Desenvolvimento Limpo. Holos, v. 4, p. 195-211. Disponível em: <http://www2. ifrn.edu.br/ojs/index.php/HOLOS/article/viewFile/1715/pdf_63>. Acesso em: maio 2015.

PETRONOTÍCIAS. (2014) Gás extraído de aterro sanitário passa a ser consumido pela Reduc. PetroNotícias, Rio de Janeiro. Disponível em: <http://www.petronoticias.com.br/archives/52304>. Acesso em: mar. 2015.

REICHERT, G.A. (2014) Painel 4 - Tecnologias apropriadas para o tratamento dos resíduos sólidos. In: SEMINÁRIO NACIONAL DE RESÍDUOS SÓLIDOS, DESAFIOS PARA IMPLANTAÇÃO DA POLÍTICA NACIONAL, 11., ABES. Brasília: ABES. Disponível em: < http://www.abes-df.org.br/upload/estudo/2014_08_19/41-geraldoreichert-tecnologias.pdf>. Acesso em: abr. 2015.

RIO DE JANEIRO. (2014) Secretaria de Estado do Meio Ambiente. Plano Estadual de Resíduos Sólidos do Rio de Janeiro. Diagnóstico dos Resíduos Sólidos. Rio de Janeiro: Secretaria de Estado do Meio Ambiente. v. 2, tomo I. Disponível em: <http://www.rj.gov.br/web/ sea/exibeconteudo?article-id=1941406>. Acesso em: jun. 2015.

ROSA, A.L. (2014) Aproveitamento energético do biogás a partir de RSU: desafios tecnológicos e regulatórios". In: SEMINÁRIO NACIONAL DE RESÍDUOS SÓLIDOS, DESAFIOS PARA IMPLANTAÇÃO DA POLÍTICA NACIONAL, 11., ABES. Brasília: ABES. Disponível em: <https://docplayer.com.br/51676712Aproveitamento-energetico-do-biogas-a-partir-de-rsu-desafiostecnologicos-e-regulatorios.html>. Acesso em: maio 2015.
SANTO, F.E. (2013) Estimativa do aproveitamento energético do biogás gerado por resíduos sólidos urbanos no Brasil. Dissertação (Mestrado) - Universidade de São Paulo, São Paulo.

SÃO PAULO. (2008) Usina termelétrica aproveitará gás do aterro São João. São Paulo: Secretaria Executiva de Comunicação. Disponível em: <http://www.prefeitura.sp.gov.br/cidade/secretarias/ comunicacao/noticias/?p=124137>. Acesso em: maio 2015.

SILVA, T.N. (2006) Diagnóstico da produção de biogás de um aterro sanitário: estudo de caso no aterro Bandeirantes. Dissertação (Mestrado) - Universidade do Vale do Itajaí, Itajaí.

SOCIEDADE BRASILEIRA DOS ESPECIALISTAS EM RESÍDUOS DAS PRODUÇÕES AGROPECUÁRIA E AGROINDUSTRIAL (SBERA). (2015) ABNT deve definir neste mês norma para biometano. Concórdia. Disponível em: <http://sbera.org.br/ pt/2015/O7/abnt-deve-definir-neste-mes-norma-para-biometano/>. Acesso em: jun. 2015.

SOLVI SOLUÇÕES PARA A VIDA. (2011) Energia a partir do biogás. Solvi Soluções para a Vida, São Paulo, n. 15, p. 8. Disponível em: $<$ http://www.solvi.com/wp-content/uploads/2015/03/revista-solvi15-pt.pdf>. Acesso em: jul. 2015.

TURIONI, F. (2014) Entra em operação $1^{\text {a }}$ usina do interior de SP a gerar energia à partir do lixo. G1, Ribeirão Preto, Franca, Disponível em: <http://g1.globo.com/sp/ribeirao-preto-franca/noticia/2014/08/ entra-em-operacao-1-usina-do-interior-de-sp-gerar-energia-partirdo-lixo.html>. Acesso em: maio 2015.

UNITED NATIONS FRAMEWORK CONVENTION ON CLIMATE CHANGE (UNFCCC). (2O15) Project Search. Disponivel em: <http:// cdm.unfccc.int/Projects/projsearch.html>. Acesso em: jun. 2015. 